\title{
A Silent Production, both of Text and Self: Conceptualizing the Psychic Work of Comics Reading
}

\author{
DAVID LEWKOWICH \\ University of Alberta \\ NICHOLAS JACOBS \\ University of Alberta
}

\begin{abstract}
In this paper, we wonder how comics - through its play of absence and presence, and as unique multimodal merger of visual arts and literature - may allow readers to engage in a particular kind of psychic work, involving the influence of memory and unconscious life on reading experience. We thus discuss an explicitly psychoanalytic understanding of reading comics, paying particular attention to the mental movements of repression, projection, and reparation. Drawing on readers' experiences with Lynda Barry's The Freddie Stories, we also consider how the formal elements of comics reading might allow readers to work through the effects of potentially difficult personal histories.
\end{abstract}

\section{Introduction}

For contemporary readers, the very idea of comics might conjure up a multitude of diverse, and perhaps even contrary uses and associations: of cartoon strips and spaces of childhood wonder and fantasy; of characters as varied as Maggie Simpson, Moomin and Wolverine; as "mentor texts" for the composition classroom (Cook \& Kirchoff, 2017, p. 77); as cause for adolescent adventure and intrigue; as a way to engage youth in discussions of critical literacy (Brown \& Begoray, 2017); and from the graphics of an airplane safety guide to an accessible medium for reaching the needs of struggling students. Though "once considered pure junk" (Chute, 2008, p. 452), it now appears that reading comics can serve a variety of uses: from entertainment, diversion and reverie, to education and information. Moreover, from data suggesting that comics account for the fastest growing sector of the North American publishing industry (NPD Group, 2017), to the inclusion - for the first time - of a graphic novel on the 2018 longlist of the Man Booker Prize, there is no doubt that attention needs to be paid to the ways in which comics contribute to contemporary modes of literacy engagement. However, as educational researchers interested in the emotional uses of reading experience, especially in relation to graphic narratives of adolescent life (one of us is an Assistant Professor of English Language Arts, and the other a doctoral student in secondary education), we wonder how comics - as a unique "multimodal ensemble" (Serafini, 2015) of visual arts and literature - may also allow readers to engage in a particular kind of psychic work, involving the insistent influence of memory and unconscious life on reading experience. In this paper, we explore how memory inevitably interacts with emotion in the production of meaning in comics reading.

Employing an explicitly psychoanalytic lens (which implies a concern for, and recognition of, unconscious processes), we thus pose the following question throughout this paper: How might the formal devices of comics allow readers to work through the 
effects of potentially difficult personal histories? By formal devices, we refer to those elements of a comic's layout and design that are particular to the aesthetic conventions of sequential art and graphic narrative, including: panels, gutters (the spaces between panels), and various illustration and panel-to-panel transitioning techniques. In this paper, we focus primarily on the mystery of that which happens in the space of the gutter, effectively theorizing the transactional possibilities of comics reading, which as Rosenblatt (1994) described, involves attention to both "external reference" and "internal response": "The reader's attention to the text activates certain elements in his past experience" (p. 11). It is because of Rosenblatt's advice that we analyze reading experience "inductively" (p. 6), while simultaneously paying attention to the influence of the text as "external reference"including comments from a group of readers, while at the same introducing a variety of scenes from a graphic novel.

By focusing on difficult personal histories, we draw an explicit connection to the concept of difficult knowledge, a term originally introduced by Deborah Britzman (1998, 2000), but since taken up by numerous other scholars in a variety of educational disciplines (Cohen-Evron, 2005; Garrett, 2017; Simon, 2011; Zembylas, 2014). As Farley (2009) has written, a text that deals with difficult knowledge "is difficult not only because of its inclusion of traumatic content," but also because such content poses a considerable challenge to readers, "who, in efforts to understand such knowledge, may be confronted with affective traces of an internal history made from primal helplessness, disillusionment and crises of authority" (p. 539). In brief, since "the creation of a work of art is in excess of the artist's intentions" (Britzman, 2004, p. 255), texts dealing with traumatic content may permit, summon, or cause readers to confront the lingering consequences of their own traumatic histories.

Though much of what follows remains a purely speculative discussion regarding the effects of comics reading, as mentioned above, we also turn briefly to readers' actual experiences, drawing from a study conducted by Lewkowich in 2017 with undergraduate students in the Department of Secondary Education at the University of Alberta. ${ }^{3}$ Working with seven participants, this study involved future high school English Language Arts (ELA) teachers in a process of collaborative interpretation with contemporary graphic novels focused on adolescent life and educational situations. As a group, participants met once a month to discuss a different text, and though we also conducted individual preliminary and paired exit interviews, the brief comments that appear in this paper come from their group discussion of Lynda Barry's (2012) The Freddie Stories. This novel - told through a series of four-panel narratives, traces a year in the life of Freddie, a young adolescent who endures bullying, abuse and teasing at school, and eventually suffers a severe dissociative episode, experiencing hallucinatory visions, emotional detachment, and a vastly distorted perception of reality. This is admittedly a dark and traumatic narrative, and given the suffering that Freddie endures, it is no surprise that numerous readers responded with their own stories of difficult and traumatic adolescent histories. Since this

3 The larger study also involved a second research site in Ontario, but for the purposes of this paper, we have only included comments from participants at the University of Alberta. 
was the third text that readers encountered as part of this study, ${ }^{4}$ they had thankfully already established a collective sense of trust and rapport. The participants whose comments appear in this paper are:

1) Corey: 21-years-old, originally from Edmonton. He swam competitively for over a decade, has an abiding interest in film studies, and openly described his history of acute depression since early adolescence.

2) Heather: A 21-year-old Indigenous woman from a First Nations community outside of Edmonton. She speaks English and Cree, and first fell in love with graphic novels after reading Robertson and Henderson's (2012) 7 Generations: A Plains Cree Saga.

3) Megan: 30-years-old, originally from Edmonton and with a previous degree in Fine Arts. Along with teaching, she also envisions herself working in arts programs at youth outreach centres.

4) Suzanne: A 21-year-old Indigenous woman from a small town in Northern Alberta. Like Heather, she also speaks Cree, and though she is a poet (who writes in English), she described her relationship to this language as fractured and estranged: "It kind of feels like English just doesn't belong to me, or I don't belong to it."

In their opening responses, these readers noted the confusing and emotionally challenging qualities of Barry's text, as many of them were transported back to scenes from their own adolescent past. As Corey described, "I still have a lot of lingering questions ... I reread several passages over and over and over again and I still don't know exactly what happened there, what it's about." Megan agreed with Corey's assessment, and suggested that perhaps this sense of feeling lost as a reader relates closely to the graphic novel's subject matter: "I really feel like it's about childhood trauma," she told us, but "from the perspective of somebody experiencing it, who does not know that they're going through [it] ... So of course, nothing makes sense and there's all this scary stuff happening." Though she shared that she "didn't have any trouble getting through" The Freddie Stories, Megan nonetheless also noted the metaphorical weight that her reading assumed: that "it was very heavy," as what she titled the "implied darkness" in the narrative "sunk into my consciousness and stayed with me for a few days." Heather described that as she was reading this book she often felt angry and sad, and that these emotional responses were also connected to a recognition that Freddie's story represents the reality of childhood for many people: "I think overall," she told us, "I felt very much upset at it, because I was like, 'This is some bullshit that happens on a daily basis to a lot of kids'." As she also experienced "a lot of flashbacks" to her own childhood, Heather found herself contemplating "how fleeting childhood and adolescence really is, and how there are so many kids that don't really have a childhood. It just really brought a lot of things home for me." Noting that her reading experience left her "really emotional and ... really confused," Suzanne also felt a deeply personal connection to Barry's novel: "It reminded me of parts of my adolescence," she explained, and "it made me think of people that used to be in my life that are not anymore ... and you wish that you could say things to them but you can't."

4 The participants also read Jillian and Mariko Tamaki's (2010) Skim, Raina Telgemeier's (2012) Drama, and Lisa Wilde's (2015) Yo Miss: A Graphic Look at High School. 
Despite this initial sense of regret, however, Suzanne described that by the end of her reading she felt "moved to write," suggesting that - more than simply a deadening weight - the emotionally "heavy" nature of this graphic novel may also potentially inspire readers to enact a change, towards articulation, in their own lives.

In this paper, we discuss how readers' memories and emotional lives may be influenced, and activated, by the formal features of comics art. The following section discusses a psychoanalytic understanding of reading comics, paying particular attention to the mental movements of repression, projection, and reparation. Considering how readers may use their reading experiences to work through difficult personal histories, we then consider the relationship between trauma and personal memory. Linked as it is with time, we then proceed from memory to further explore the question of temporality, including a distinction between chronos and kairos time. While the first remains corporeally bound, the second describes the alternately retroactive and prospective glimpses that may potentially appear in the reader's unconscious, engaged in reading experience.

\section{Reading Comics Psychoanalytically: Repression, Projection, \& Reparation}

\section{The Gutter}

Exploring the value that psychoanalytic discourse offers the study of comics' reception, Contreras-Koterbay (2008) has emphasized two particularly interrelated aspects of this art form, especially as it materializes in the context of reading experience: the gutter, and its indeterminate relation to a multiplicity of images. As he defines it, the element known as the gutter is "the empty space between panels, typically sustaining unseen information and narrative that the reader fills in, completes, regardless of the continuity or discontinuity between panels" (p. 90). In reading a comic, the reader is enticed to scan from panel to panel, across a multiplicity of variant images - sometimes in a structured and unified motion, perhaps continuously from left to right, and other times in a less organized fashion, perhaps vertically or zigzagged and diagonally recursive. However, regardless of how the author places their images on the page, the gutter provides an absence of space, which paradoxically, also works to simultaneously delimit a spatial presence. If we look at the following example from The Freddie Stories, we can see that in the gutter between Freddie's dream and the moment of wakefulness, this absence that is also a presence suggests a space of mental and physical transformation for the character, which is at the same time precisely where the reader creates and assumes their version of narrative meaning. 

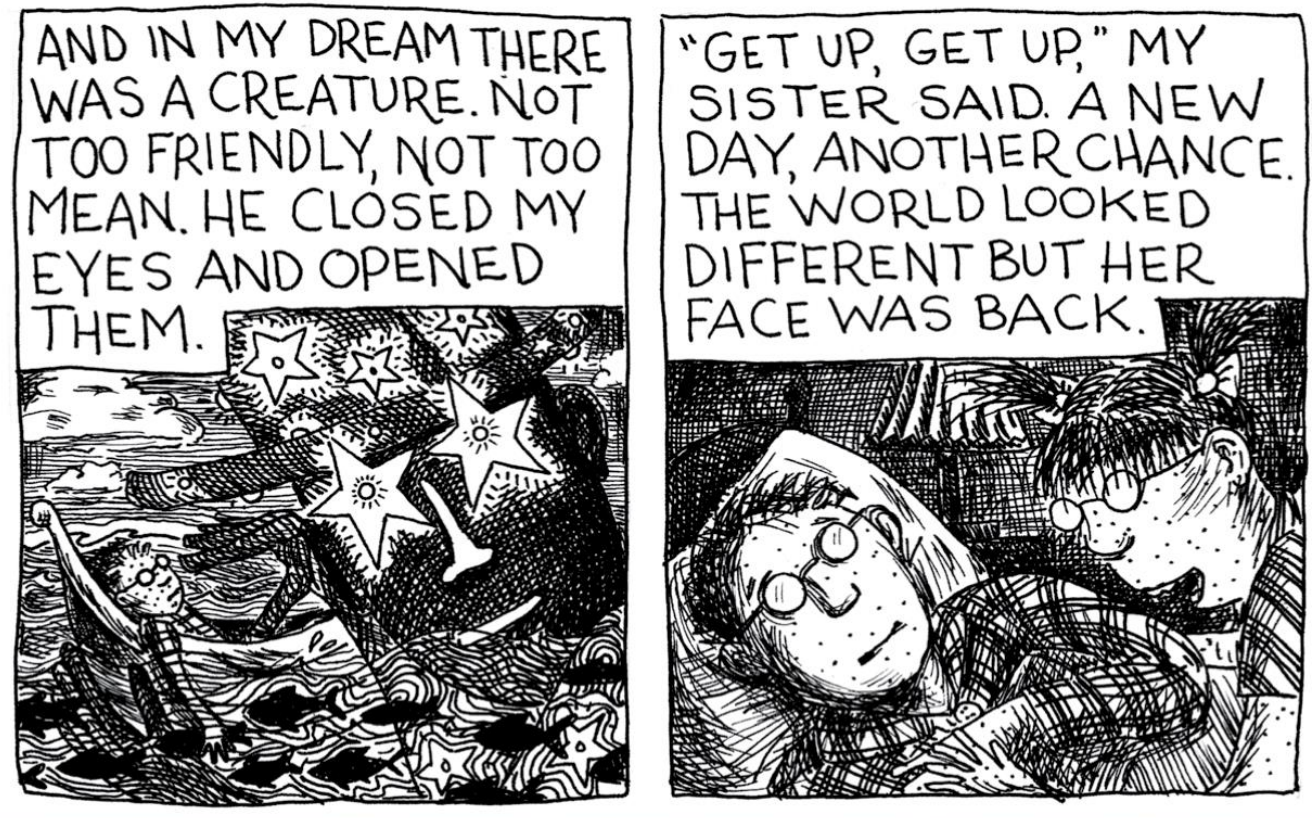

Figure 1. A New Day, Another Chance

The gutter between two images, representing a temporal snapshot of textual space, marks a boundary: the beginning and the ending of each image, seemingly frozen in space and time. These images, though, are perceived by the reader as continuous and vastly alive, moving across and through the space of the gutter, which seamlessly carries the narrative forward. The narrative boundaries in reading comics are thus contained and created by the gutter, simultaneously an empty space and - through the reader's influence - a space where reading persists. Within the gutter, whose emptiness is its function, the artist is not required to include a single thing, indicating this art form's absolute "dependency upon the reader to fill in the blanks" (p. 90). In the "productive activation" (Bennett, 1983) of reading, the stillness of the gutter is therefore stirred to life and filled with unpredictable manifestations of the reader's unconscious. Moreover, even though the gutter may assume a variety of different shapes, and does not always have to follow a strict pattern of spaces between panels, because of the non-continuous nature of comics narrative (a continuous version, in which we see everything that takes place, might more closely resemble a film), there are always empty spaces in comics that function as a gutter might.

\section{Closure and Projection}

As McCloud (1994) has indicated, though "comics panels fracture both time and space," the element of closure enables readers, "to connect these moments and mentally construct a continuous, unified reality" (p. 67). In the above example, for instance, it is presumed that Freddie moves from sleep to wakefulness across the gutter, which therefore establishes a continuity between these otherwise disparate psychic states. In psychoanalytic terms, the gutter is filled (or closed) with an unending series of projections from the 
reader's unconscious: "Comics seem to be an alchemy of the reader's making, an opportunity for ... free play" (Contreras-Koterbay, 2008, p. 91). However, given that certain elements of the reader's unconscious emotional past - activated in reading experience and projected onto the gutter - may have previously been forgotten or repressed by the reader's psyche, this "play" is not necessarily always innocent or carefree. As we presume Freddie's movement to wakefulness, we also may be momentarily reminded of our own experiences with nightmares and disturbing dreamscapes, which until this moment of reading may have otherwise been forgotten. As a defensive strategy of psychic survival, repression "hides forbidden parts of the self from itself" (Farley \& Robertson, 2009, p. 83), which leads us to question if comics may serve a similar function to a broader purpose of psychoanalytic work: namely, to "overcome resistances due to repression" (Freud, 1914, p. 148). Importantly, we should note that unlike practitioners of bibliotherapy, we are not concerned with using comics as prescriptive and therapeutic tools, but rather, seek to describe a psychic function of reading comics, and how it allows readers to potentially play with (and dream) their inner histories.

In her characterization of contemporary reading practices, Gallop (2000) argued that the majority of reading involves the work of projection, where the reader unconsciously enforces their own understanding upon another's creative work. Unlike McCloud's (1994) celebration of closure, however, Gallop reads this work of projection as a serious failure. "Projecting is the opposite of learning," she noted, "As long as we project onto a text, we cannot learn from it, we can only find what we already know" (p. 11). As a way to avoid such failures of learning, Gallop suggested that a strategy of close reading, involving a sustained focus on the seemingly insignificant details of what we read, might function as a "safeguard against projection" (p. 11). Though Gallop is certainly correct in assuming that if all reading is projection we can hardly move past what we think we already know, in the context of comics, we nonetheless question if readers can ever read closely enough to completely safeguard against projections, or if this is even desirable. As mentioned above, and by its very nature, a comic relies upon the boundaries created by the spaces between its frames, and given that it must be filled to achieve a sense of narrative closure, the reader has no choice but to close these gaps (be they chronological, affective, narrative, spatial, etc.). Or, to put it otherwise, given the non-continuous narrative structure of the graphic novel, the reader has no choice but to project - the reader's unconscious life, whose "constitutive condition" refers to "obscure knowledge ... which no consciousness can master or be in possession of" (Felman, 1977, p. 128), is therefore an essential and inescapable element of comics reading.

\section{The Work of Memory, Repression, and Reparation}

Especially when it comes to graphic narratives about adolescent life, the work of closure often presumes a certain knowledge regarding the shape and surroundings of contemporary educational structures. For example, if we consider a relatively insignificant sequence from The Freddie Stories, we can recognize the importance that a reader's history of school inevitably bear on how they contextualize narrative meaning. 


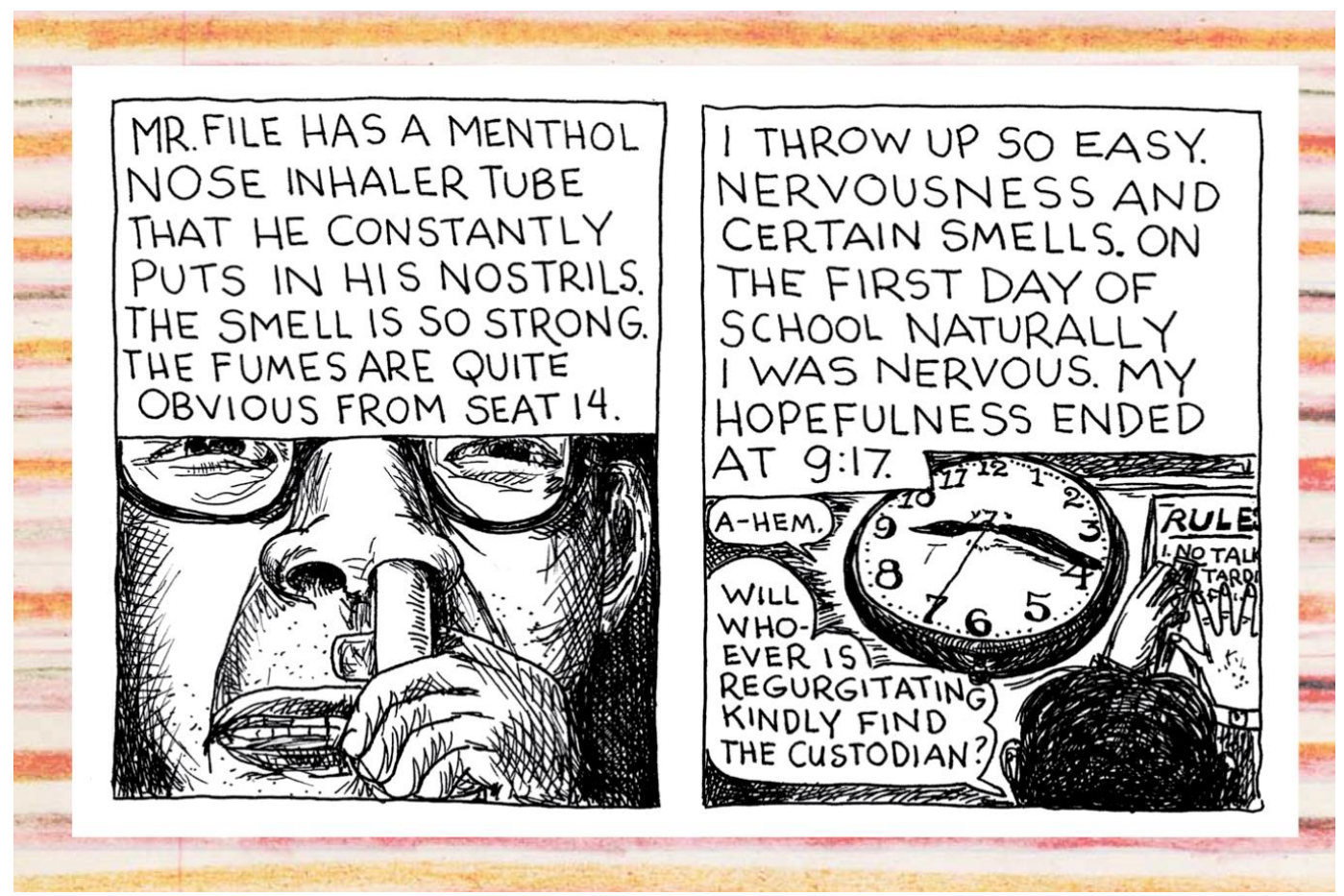

Figure 2. Nervousness and Certain Smells

Early in the novel, over a series of four panels, we find Freddie in class on the first day of a new school year, and though he enters with an optimistic attitude - "The first day of school is a most hopeful day" (p. 42), he tells the readers - by the end of the four panels, his sense of enthusiasm has already all but faded: "My hopefulness ended at 9:17" (p. 43). On p. 43, we are shown a close-up of Freddie's teacher, Mr. File, sticking an object into his nose, as Freddie narrates this grotesque scene: "Mr. File has a menthol nose inhaler tube that he constantly puts in his nostrils. The smell is so strong. The Fumes are quite obvious from seat 14" (p. 43). As readers, and having passed through (at least superficially) comparable institutions and experiences of education, these potent images work to bring us back to a series of scenes from personal history. Though multiple, we will share one as an example:

Reading this scene, I (Lewkowich) am immediately transported back to the image of my grade nine Physical Education teacher, who anytime he would lose his temper, a tiny spot of spittle would form on the end of his lips, resting there immobile, throughout the entire time he was venting his frustrations, yelling madly, at the group of students of which I was inevitably a part. I have no memory of anything else he said or did, but this spot of spittle stays in my mind as a potent reminder of the seemingly uncontrollable nature of the teacher's body-also, that teachers can never control the meanings that students produce.

In the fourth panel, just over the space of the gutter, Freddie explains what has already happened: "I throw up so easy. Nervousness and certain smells." 
This brings me close to the foul smells I cannot help but free-associate with school: objects that smell like urine, rotting food, groups of sweaty boys, unwashed clothes, near-mouldy socks, boiled hot dogs, coffee breath on my History teacher's mouth, hints of whisky on another.

In the image of this fourth panel, we see Mr. File posting his class rules, directly next to the clock that is identical to that which many readers will quickly recognize as that of a powerful "mental image" (Lemieux \& Lacelle, 2016); the clock that, in all likelihood, appears in each and every memory they form of school. Despite its quickness, this scene undoubtedly positions the reader as someone familiar with school, its bodies and smells, who fills the gutter between the mention of a teacher's scent and a student's vomit with all degrees of conscious and unconscious personal history and association.

Although this example is relatively straightforward, graphic novels about adolescence often encourage the reader to project themselves into similar environments, inevitably involving the reader's lived experiences, including their thoughts, emotions, and various somatic histories of being in school. Considering that a reader's emotional history is often involuntarily linked to "resistances due to repression" (Freud, 1914, p. 14), these identifications in reading may also potentially connect to difficult moments from the reader's adolescent past, experiences that - given how what is unconsciously repressed, though it may be removed from conscious remembrance, never actually disappears in full - may be felt rather than clearly understood. An otherwise innocent scene may therefore potentially provoke the reader to experience a wide variety of unpredictable and seemingly incongruous emotions, including (but hardly limited to) distress, loneliness, despair, nervousness, boredom, dejection, anxiety, heartache, and sadness.

Far from this encounter being necessarily a bad thing, however, when readers brush up against difficult feelings and inner histories, there is also the possibility of the reader encountering, in projection, what Klein (1937/1964) has titled a "drive to reparation." As a way for the reader to process past experiences and memories in meaningful ways, reparation is "a painful labour through which the subject attempts to make amends - to restore or to compensate for the losses that inevitably come with living, loving, and learning" (Farley \& Robertson, 2009, p. 90). As Grumet (1998) has written, "Reading invites us to recuperate our losses. As we enter into the fictive world and emerge from it, we experience the opportunity to reconsider the boundaries and exclusions that sustain our social identities" (p. 27). Though reading remains a necessarily individual experience, it may also therefore allow the reader to study the ways that self is actually an effect of earlier social relations - of "living, loving, and learning" (Farley \& Robertson, p. 90).

This possibility for reparative psychic work is also affected by the manner that comics reading is always mediated - always and necessarily interrupted - by the inevitable influence of interpretively uncertain images. "In this way," Wolfreys (2000) noted, "reading not only opens itself, it remains open to the force imposed upon it by the structure of the text, that which causes the reading to swerve" (p. 56). Rather than simply a blank canvas, upon which the reader projects unconscious thoughts, the gutter functions as a liminal space between the concerted influence of multiple aesthetic forces. It is therefore a powerfully persuasive textual gap that, due to its structural indeterminacy - an emptiness that will be, must be filled, but not with anything that can ever be fully or safely predicted 
- may lead readers to question where the text ends and where they themselves begin. It is thus that we briefly return to a reader's experience with The Freddie Stories.

\section{Reading the Spaces Between}

In discussing the "reading effects" (Felman, 1977) of this graphic novel - filled with sizable gutters of similar dimensions - Corey characterized his experiences of reading the gutter as a process of "simulating what was going on in my head": "I remember visualizing," he told his reading group, "a feature film or something ... I remember trying and failing [to fill in the gaps] because ... with that story, I still have a difficult time getting together exactly what happened." Despite this participant's assertion of failure, upon reflection he was also aware of the visualization of mental effects that characterized his experiences of reading within the gutter - trying to make sense of a difficult story by reading the spaces between. As he jumped from image to image in reading, actively "simulating" his mental process of filling in the gaps of the blank textual space, this participant described his play of unconscious projection as akin to the flashes of a film reel, weaving over and simultaneously through the graphic novel.

As the gutter acts alongside the multiplicity of images in comics - a "jagged, staccato rhythm of unconnected moments" (McCloud, 1994, p. 67) - this narrative structure presents a unique potential for free play, as the reader's eyes stray interminably, recursively, across the page. Throughout their reading experience - and this is especially evident when the text in question, such as The Freddie Stories, contains interpretively uncertain images and sequences - the reader is thus repeatedly encouraged to project their "imprisoned dreams" (Pazzagli \& Monti, 2010, p. 734) onto the text, as they also strive to relay the imprisoned dreams contained in the textual images: "reading [is] constituted by a politics of openness, as well as by a politics of the opening" (Wolfreys, 2000, p. 56). To refer back once again to Freddie's transition from dreaming to wakefulness, as we read across and through the gutter, we become Freddie's dream as his dream becomes ours and the two become indistinguishable. To understand the interpretive experience of reading as one of unfastening imprisoned dreams - in the text and self - we therefore need to revisit our earlier objective: How does the particular structure of comics invite the reader to work through psychic conflicts and difficult histories? In order to venture forward, we will now consider the dynamic manifestations of traumatic history and memory.

\section{Trauma and Memory: An Indication of Temporal Scission}

\section{Childhood, Adolescence, and Traumatic Memory}

It is clear that our memories are important components of how we understand ourselves in present experience, including our reading activities. We rely on memories to shape our current behaviour, and try to learn from past experience - whether pleasurable or traumatic, and whether or not such learning is a conscious affair - as a means of shaping a preferred and desired future. Childhood and adolescence, and their persistent unconscious histories, are especially important and formative years that shape how we come to eventually understand ourselves as adults. In this context, Treacher (2000) has noted that "childhood subjectivity" - and the same could certainly be said of adolescence - "is both specific with its own dynamics while being also a preparation for, and a looking forward to, adulthood" (p. 138). In the midst of this developmental growth, there is also a letting- 
go of instinctual dependence on caregivers, eventually leading to a relatively more stable sense of individual self. Before this possibility arrives, though, young people pass through an exceedingly vulnerable and challenging time, marked by struggles "to make sense of their own and others' worlds and attempting to locate themselves and others within the social and cultural spheres" (p. 138). Given the formative nature of such years in regards to individual development, it is hardly surprising that - if adolescents experience difficult moments, traumas, or psychic conflict - these challenges may be repressed, only to reemerge uninvited in later life.

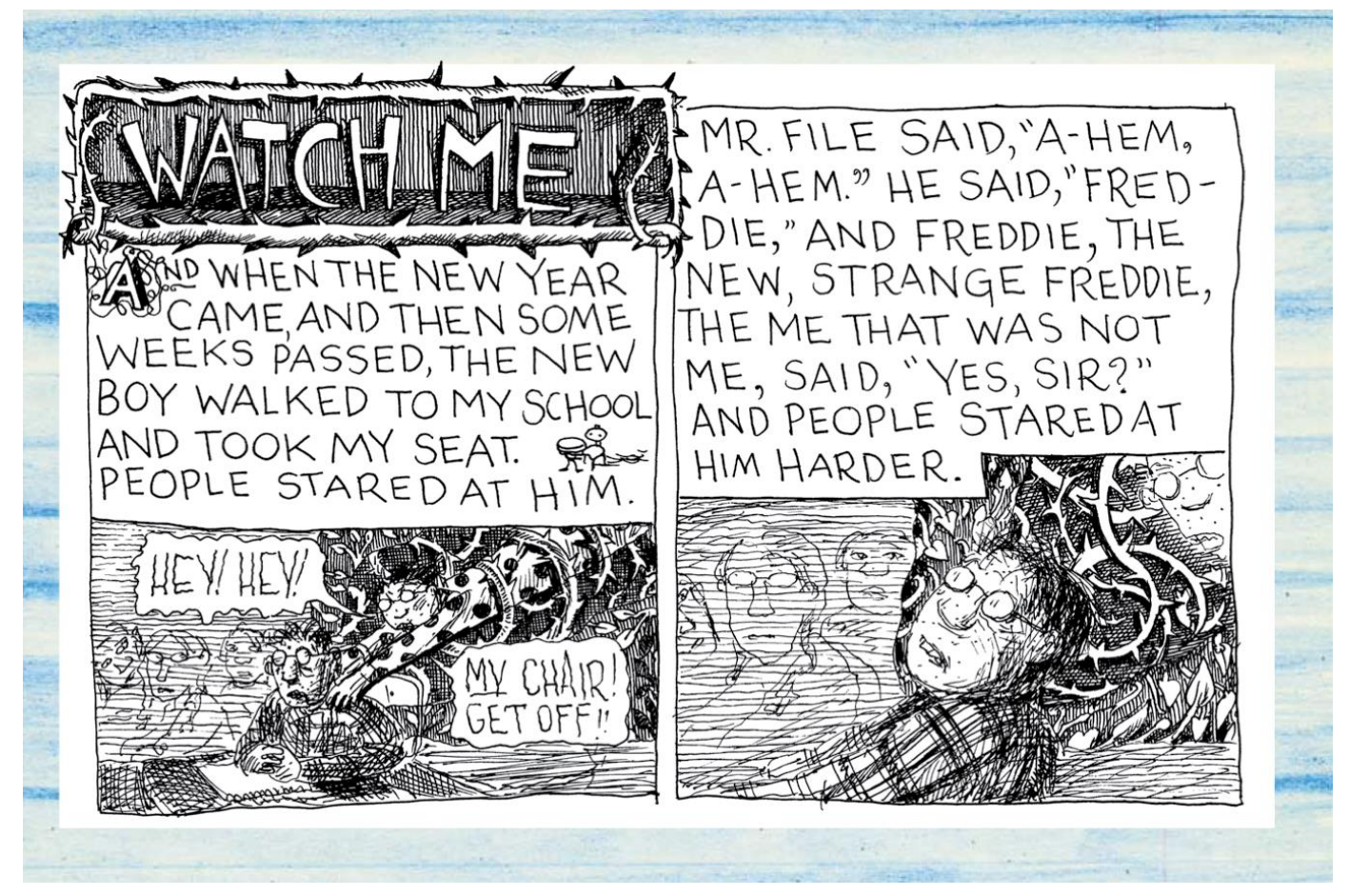

Figure 3. The Me That Was Not Me

LaCapra (2001) has described trauma as "a disruptive experience that disarticulates the self and creates holes in existence; it has belated effects that are controlled only with difficulty and perhaps never fully mastered" (p. 41). Understandably - and as with the above example from The Freddie Stories, where following a series of traumatic events, Freddie appears undoubtedly disarticulated - the experience of trauma in early life is not easily overcome. Indeed, we might better understand these "holes in existence" alongside Stern's (2017) position that "trauma, and the dissociation to which trauma leads, freezes time, which makes it impossible to formulate certain kinds of new experience" (p. 501). As with Freddie, traumatic dissociation can lead the traumatized person to experience life as a split and persistently absent subject. Such "holes in existence" are also invariably related to the individual's capacity for memory - without some memory of an experience from our past there is, of course, a gap in chronological time. In this sense, memories act as fillers of holes and spaces in time; for a hole to be created, it must in turn lack a sense of memory. And yet, while Stern has noted that trauma renders the formulation of new experience impossible, he also noted that dissociations may be eventually breached: "When 
a dissociation is breached, a piece of one's being that had been sequestered ... and therefore unformulated ... is suddenly accessible as a state of self' (p. 520). In the context of comics reading, this "state of self" may be precisely what readers encounter in the gutter, itself a "hole" in narrative existence, as projections of past experience - "never fully mastered" (LaCapra, p. 41) - become enlivened through the surrounding narrative and its indispensable gaps.

In her understanding of the comings and goings of trauma, Caruth (2016) has described such difficult experience as "an act of departure" (p. 23), reinforcing the connection between dissociation, experience, memory, and the possibilities of temporal displacement. She also noted that while trauma is "an effect of destruction," it simultaneously exists as "an enigma of survival" (p. 60). It would thus appear that, by its very nature, trauma is a paradoxical experience - it promotes psychic survival by providing protection from difficult experience and disabling the ability to create memory. Megan, one of the readers, particularly emphasized how Barry's text is "about coping mechanisms. So, no matter what people go through," she told us, "the brain comes up with coping mechanisms to survive from trauma and they don't have to make sense in any way." Especially during the formative years of childhood and adolescence, where thoughts, memories, and experiences have the potential to affect future psychological and psychosocial development, it is clear that a dissociation or hole in existence - as with the example of Freddie - might also provide a form of psychical protection. Though it may remain forever unarticulated, it is certainly simpler to manage a hole in existence than to face an experience that the psyche cannot abide, or is not yet capable of addressing.

In terms of its temporal function, Caruth (2016) also described trauma as "a shock that appears to work very much like a bodily threat but is in fact a break in the mind's experience of time" (p. 63). This image of temporal scission, which parallels the concepts of "dissociation" and "hole[s] in existence," supports the idea that - in trauma - the continuity between time, experience, and memory has somehow been fractured.

The Emotional Persistence of Forgotten Memory 


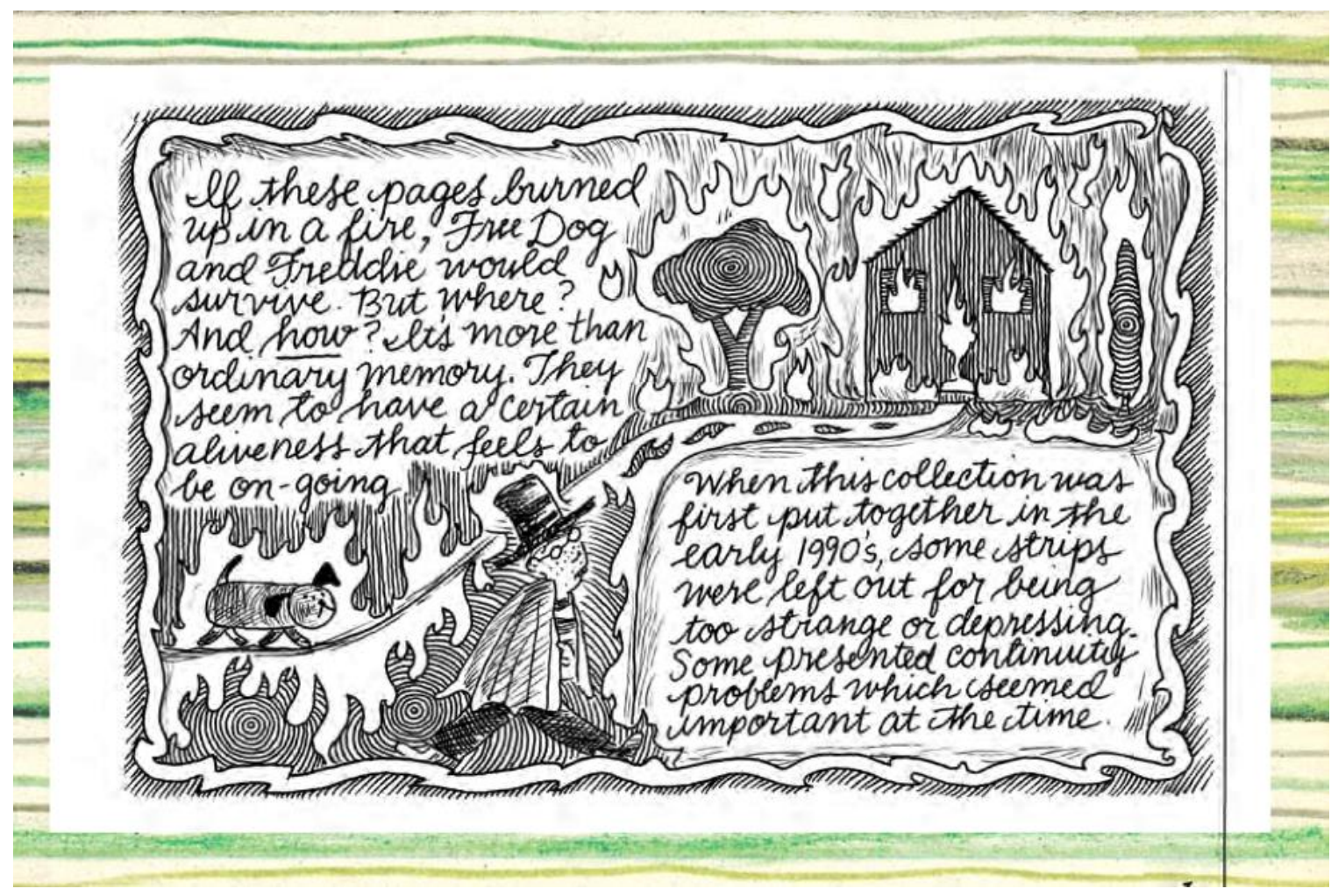

Figure 4. A Certain Aliveness That Feels to Be On-going

Turning back to The Freddie Stories, in Barry's afterword to the principal storyline (which also serves as an introduction to what she entitles a series of "lost stories"), she questions the status of certain strips that had been excluded from the initial collection of Freddie's narrative, which were either "left out for being too strange or depressing," or since they "presented continuity problems" (p. 128). Regarding these "lost stories," Barry describes how their inclusion in the present volume relates to "gaps [that] have been made for a part of the mind that abides in things which do not connect straight away" (p. 131), which is similar to Stern's assertion that a breached dissociation makes past experience "suddenly accessible as a state of self" (p. 520).

In terms of its place in reading experience, Heather illustrated this fracturing of time, and described how engaging with the final section of The Freddie Stories connected her back to a difficult childhood. Questioning how a forgotten past might nonetheless persist in an unseen place, Heather told her reading group, "The majority of my childhood is repressed":

I don't have a lot of memories from my childhood. I had a very, very abusive father, and a very, very abusive family. My mother took myself and my younger sister out of there as soon as she could ... And so, just reading [these final pages] ... the dog is burning, and Freddie is burning, and the house is burning, and it says, "If these pages burned up in a fire, Free Dog and Freddie would survive. But where?" And it made me think, if your childhood burnt up in a fire, if you couldn't remember your childhood, it still exists, but where does it exist? And it just really hit me, and 
it made me have to sit back and think, "Well, where does my childhood exist then if it doesn't exist when I was a child?"

As stated above, the psyche's refusal to remember well might be its best defense against working through the unapproachable, unendurable qualities of traumatic experience. It might also be the case, however, that memories remain central to a reader's present experience, even if - rather than simply referring to easily legible events - such memories seize upon feelings of past emotional defence. Put simply, as Heather queries, the emotional qualities of past events may still persist, even if the actual events are not themselves remembered.

Early in his career, Freud (1899/2003) understood that although memories of childhood experience are stored differently than later memories, these unintegrated, dissociated experiences could still manifest themselves emotionally. Kuhn (2000) has described the challenge of handling traumatic histories of childhood and adolescence by distinguishing between "past events and our memories of them" (p. 184), a relationship that she described as "far from imitative," since every time we approach a past event, we necessarily do so in mediated form. "The past," she noted, "is unavoidably rewritten, revised, through memory; and memory is partial: things get forgotten, misremembered, repressed ... even the memories we run and rerun inside our heads are residues of psychical processes, often unconscious ones" (p. 184). Given that memories may represent emotional residues rather than actual events, Heather's question regarding a burnt childhood - "If your childhood burnt up in a fire ... where does it exist?" - and despite her obviously difficult past, is a recognition of childhood memory itself as a fluid state of revision and re-visitation, with the powerful and unpredictable capacity to change and morph with the inevitable passing of time. In order to explore how readers might revise or rewrite memories and experiences through their engagements with comics, it is now important that we provide a brief discussion on the role of time and temporality in relation to reading experience.

\section{Comics Reading and Condensed Temporality}

Transference, Kairos and Chronos Time 


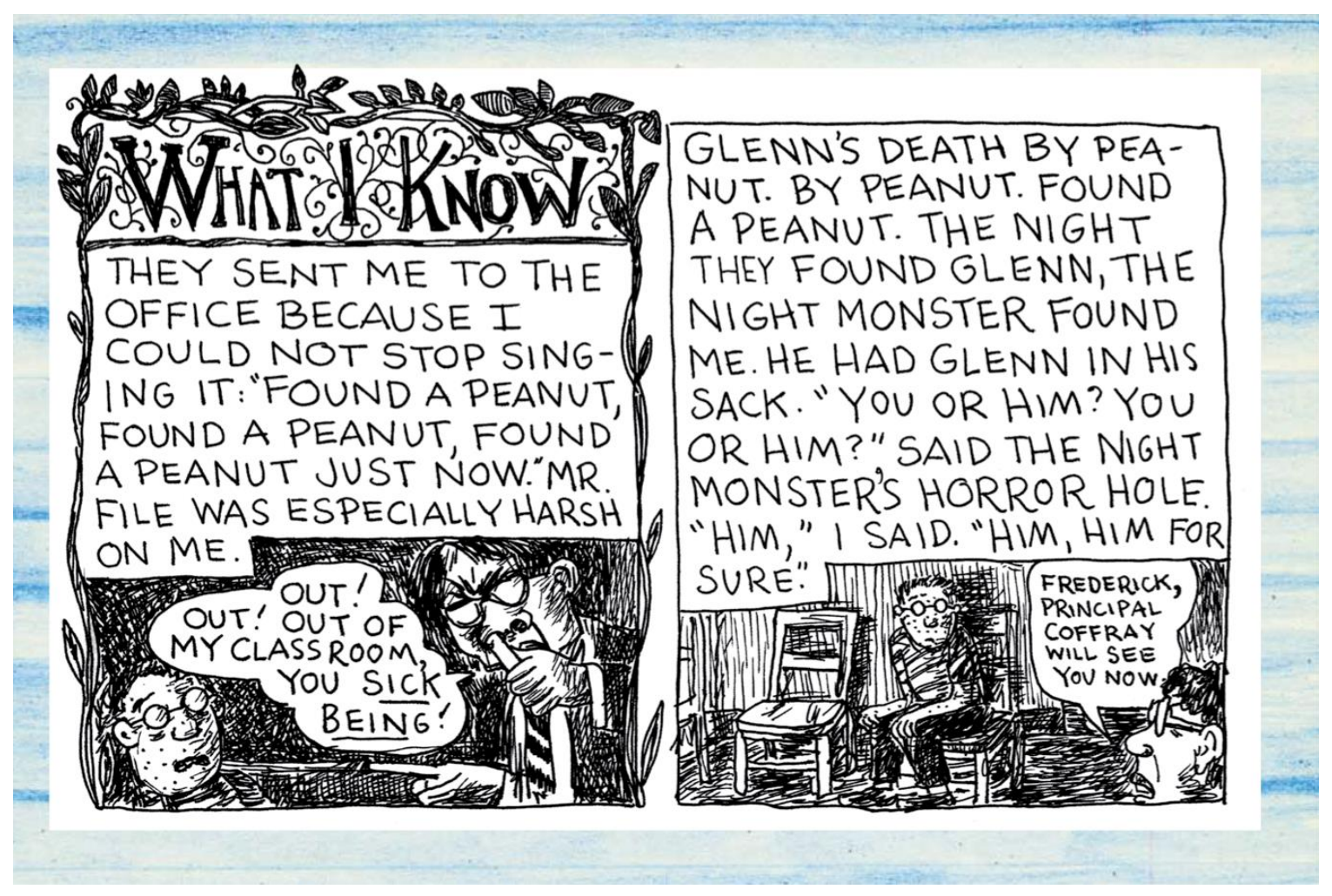

Figure 5. The night they found Glenn, the night monster found me.

Similar to dreaming, the experience of engaging with comics has the capacity to collapse a reader's sense of time, where the emotional past - as experienced in memory and through the process of transference - becomes condensed within the present context of reading, allowing the reader to encounter what Corey described, in relation to his own reading of The Freddie Stories, as "lasting psychological reverberations." For psychoanalytic theory, the transference refers to an "uncanny transportation of emotion from the past to the present" (Farley \& Robertson, 2009, p. 85), and where as Freud $(1905 / 2006)$ has noted, "earlier psychical experiences [are] brought to life not as something in the past, but as a current relationship" (p. 534). In this light, the reader's psychic capacity to revise and rewrite memories and past experiences can be seen as a powerful challenge to the idea of linear, chronological time. As with Freddie in the panels above - where he repeatedly relives the moments and conditions of a classmates' death - imagination and emotion actually work in concert to collapse time, making the past and present appear as if they are one and the same. In relation to reading experience, the transference thus affects the temporality of how and what we read. As Britzman (1998) has claimed, the challenging and unpredictable nature of the transference presents a "compromised and condensed time" (p. 33), perpetually bringing our emotional past to bear on the present of reading. Similarly, Stern (2017) has argued that, "the mind is not constructed on a linear, forward-looking basis" (p. 515), and although we typically turn to the expectations of chronological time to plan our lives, it appears that the unconscious operates upon a qualitatively different set of rules, which Stern described in relation to the concept of kairos time: "Past and present, in 
this view, are ceaselessly in the process of constructing and reconstructing one another" ( $\mathrm{p}$. $503)$.

Kairos time, in contrast to chronos time (which is accurate, measurable, and constantly flows in a straight line), is not simply limited to forward, linear motion. Instead, it moves recursively - both forwards and backwards - and is a kind of time in which "not only does the past create the present, but the present also creates the past" (Stern, 2017, p. 502). For Freddie, and though linear time has unavoidably passed, following the death of his classmate the present is felt as if it still inextricably connected to - indeed, indivisible from - the temporal past. It is kairos, under whose unconscious guidance and freedom of movement the psyche operates, that collapses temporalities, experiences and memories, allowing the reader - in the present context of reading and remembering - to effectively revisit and rewrite what has already been experienced. The meaning of experience is therefore infinitely malleable, since the mind and its retroactive functions of memory are continuously creating and recreating new meanings, based on the changing demands of contemporary life.

Comparing herself to the book's protagonist, Megan described her experiences reading The Freddie Stories as an opportunity to reconsider the difference between the actual past and how it eventually comes to be remembered:

For me, as [an adolescent], I went through a lot of confusing and intensely emotional things .... And I think that everybody, as teenagers, goes through overwhelming things, and then as an adult, we can look back and say, "Oh, that's why that was happening to me." So, you sort of amend your memories, so it's not nearly as terrifying as it was when you were experiencing it.

In reading Barry's narrative, and questioning how the "intensely emotional" nature of adolescence may eventually affect an individual's future sense of self, Megan contrasts her own adolescent experiences, through personal memory, with those of Barry's character. Appearing surprised by her current ability to rationalize her adolescent pain, Megan describes how part of becoming an adult involves a recursive process of memory "amend"ment. In this particular context, the experience of reading comics involves the reader's capacity to collapse time - including a reconsideration of their own experiences of adolescence, rewritten and revised through the condensations and displacements of personal memory. Since the comic stirs up feelings whose precise histories might well be totally beyond the reader's conscious grasp, the artistic work invites the reader to fill in the gaps of their own experience, as they also fill in the textual gaps of the gutter.

\section{A Momentary Rupture of Chronos Time}

The physical body, existing in the present moment of reading, is bound by the strictures of chronos time. The hands hold the book and the eyes actively scan the page, ever unfolding into the future. The reader's unconscious, though, projecting and reflecting upon the necessary gaps in meaning that comics presumes, is not bound by the same constraints as those of the body. Instead, the unconscious traverses between the past, present, and future, and - operating through the plasticity of kairos time - makes no determination or priority between these temporal states. The comic is therefore a catalyst for emotional remembering, bridging dissimilar elements of human experience - that of 
the body and that of the mind - each of which is governed by a different conceptualization of temporality. While Contreras-Koterbay (2008) has written of comics as an "opportunity for ... free play" (p. 91), this "play" may here be described as a momentary rupture of chronos time, which allows the reader to dream - along with kairos time - across the seemingly immovable boundaries of past, present, and future. Perhaps unsurprisingly, then, this temporal rupture also partly describes the goal of transference in psychoanalytic therapy, where play involves a precarious movement between internal and external reality: "In playing," Winnicott (2005) claimed - and we may here substitute playing for reading - the patient, or the reader, "manipulates external phenomena," such as a graphic novel, "in the service of the dream and invests chosen external phenomena with dream meaning and feeling" (p. 70).

Discussing the practice of reading graphic novels about adolescence, Megan explicitly described her experience in this study as similar to that of therapy:

It definitely brought up a lot of old memories ... It was a little bit like therapy... just revisiting your old perspectives and stuff like that, and having that chance to reflect on how those years shaped me ... and it made me think a lot about how I would have felt if I had read that at the age of sixteen.

Though it certainly is not exactly the same as therapy, the collapse of time encountered in Megan's reading experience presents a similar potential for transformation - a chance to integrate, though moments of emotional transference, past and present psychic experience. For the adult reader, it thus appears that graphic novels about adolescent experience may act as "a psychic bridge that connects us to the deepest structures of our minds, our bodies, and our relationships to others" (Farley \& Robertson, 2009 , p. 92), creating a link between one's present experience and the emotional situation of adolescence.

\section{Reading as Re-visitation}

As we have previously stated, the experience of adolescence is often marked by periods of psychic and emotional struggle, and a difficult movement towards an understanding of self apart from others - a time, as Matthews (2009) noted, "negotiated via the pushes and pulls of letting go of the child-self even as adulthood beckons" (pp. 6263). If these years are especially marked by difficult moments, especially those where language fails, memory itself may be rarely admitted in full to the conscious mind, and only in the future may the adult be tasked to revisit these emotional claims. Suzanne described this process of re-visitation (again, in response to The Freddie Stories) as a way to reconnect with forgotten, social bonds from her past, and a means to finally symbolize a difficult personal history:

Reading this, it was ... a sad experience. It was kind of healing in a way because ... I was able to make those connections. I realised that there are parts of me that are hurting that I never even knew were there. And so, [reading this graphic novel] made me think of that. And just how I see myself, so very connected to the people that are in my life. And when they're hurting, I'm hurting, too. So ... it was nice to have something to relate that back to, and it was a way for me to deal with some of 
those hard feelings. And by the end, I was able to write and release some of those emotions.

In reading Barry's story about adolescence, Suzanne was able to reconnect with her own adolescent past, encountering and articulating a series of difficult memories and emotions, and in doing so, understanding them - "deal[ing] with some of those hard feelings" - in a way that moves from a failure to a practice of symbolization, an important and necessary component of reparative work. As Segal (1973) noted, reparation is "based on the recognition of psychic reality, the experiencing of pain that this reality causes and the taking of appropriate action to relieve it" (p. 95). Explicitly characterizing her creative efforts as a form of reparation, a process that she describes as writing and releasing, Suzanne is thus newly able to experience her personal history as more than emotional manifestation - embodying past feeling in the symbolic structure of language and poetry.

\section{Conclusion}

Conceptualizing reading experience involves a consideration of how the reader incessantly invents himself or herself throughout the text: a "silent production" referred to by de Certeau (1984) as including "the drift across the page, the metamorphosis of the text effected by the wandering eyes of the reader, the improvisation and expectation of meanings inferred from a few words," and with reference to the fact that readers can choose to read in whichever direction they wish, "leaps over written spaces in an ephemeral dance" (p. xxi). In the context of comics, however, this phenomenological description of reading is made increasingly more complex through the conspicuous inclusion of an empty space - the gutter - in the very fabric of the graphic narrative itself, through which the reader is invariably compelled to make meaning. Moreover, as we have discussed above, this meaning that the reader creates is unavoidably linked to the psychoanalytic notion of projection, which we here describe as the psychic work that occurs in the textual space of the gutter, where readers encounter their forgotten selves, and through which a previously disavowed past may eventually be brought to articulation.

In particular for adult readers of adolescent graphic narratives, such encounters may be fraught with an unexpected emergence of negative affect, perhaps even verging on an emotional experience of trauma. Though much of adolescence and childhood may be stripped from conscious remembrance, the more difficult details of these years may remain as unconscious emotional remnants, inaccessible and unfamiliar - as Suzanne expressed, "parts of me that are hurting that I never even knew were there" - until brought to awareness through an unpredictable moment of textual uncertainty that, as in a dream, is precisely where, as readers, we tend to let our defences down. In this respect, comics themselves - especially given the history of their assumed cultural status as disposable objects, facile, juvenile, and innocuous - may take readers by surprise, especially if they deal with challenging subject matter, such as in The Freddie Stories.

However, given that a reader's responses are never predetermined, the reader's inherent inventiveness presents the possibility that, from the fragments of disillusion and disenchantment, a process of symbolization may emerge that thinks anew the meaning of text, at the same time as the reader's past is brought - through kairos time - towards a future space of reparative self-relation. Finding in reading a lost history, the reader "combines their fragments," both of text and self, "and creates something un-known in the 
space organized by their capacity," again, both of text and self, "for allowing an indefinite plurality of meanings" (de Certeau, 1984, p. 169). At the very least, through conceptualizing the psychic work of comics reading, we present such reading as necessarily dependent on the interplay between uncertain structures of absence and presence, and though by this time it hardly needs repeating - such holes and spaces, and holes as spaces, that are both of text and self.

\section{References}

Barry, L. (2012). The Freddie stories. Montreal, QC: Drawn \& Quarterly.

Bennett, T. (1983). Texts, readers, reading formations. Bulletin of the Midwest Modern Association, 16(1): 3-18.

Britzman, D.P. (1998). Lost subjects, contested objects: Toward a psychoanalytic inquiry of learning. Albany, NY: SUNY Press.

Britzman, D. P. (2000). If the story cannot end: Deferred action, ambivalence, and difficult knowledge. In R. I. Simon, S. Rosenberg, \& C. Eppert (Eds.), Between hope and despair: The pedagogical encounter of historical remembrance (pp. 2757). Lanham, MD: Rowman \& Littlefield.

Britzman, D. P. (2004). Monsters in literature. Changing English, 11(2), 253-265.

Brown, A., \& Begoray, D. (2017). Using a graphic novel project to engage Indigenous youth in critical literacies. Language and Literacy, 19(3), 35-55.

Caruth, C. (2016). Unclaimed experience: Trauma, narrative, and history. Baltimore, MD: JHU Press.

Chute, K. (2008). Comics as literature? Reading graphic narrative. PMLA, 123(2), 452465.

Cohen-Evron, N. (2005). Students living within violent conflict: Should art educators "play it safe" or face "difficult knowledge"? Studies in Art Education, 46(4), 309322.

Contreras-Koterbay, S. (2008). Psychoanalysis and comics: A partial Lacanian ontology. Notes in the History of Art, 27(2/3), 90-95.

Cook, M. P., \& Kirchoff, J. S. J. (2017). Teaching multimodal literacy through reading and writing graphic novels. Language and Literacy, 19(4), 76-95.

de Certeau, M. (1984). The practice of everyday life (S. Randall, Trans). Berkeley, CA: University of California Press.

Farley, L. (2009). Radical hope: Or, the problem of uncertainty in history education. Curriculum Inquiry, 39(4), 537-554.

Farley, L., \& Robertson, J. P. (2009). The stranger side of education: A dialogue with psychoanalysis. In C. Levine-Rasky (Ed.), Canadian perspectives on the sociology of education (pp. 81-99). Don Mills, ON: Oxford University Press.

Felman, S. (1977). Turning the screw of interpretation. Yale French Studies, 55/56, 94207.

Freud, S. (1899/2003). Screen memories (D. McLintock, Trans.). In A. Philips (Ed.), The uncanny (pp. 1-22). London: Penguin.

Freud, S. (1905/2006). Fragment of an analysis of hysteria (Dora). (S. Whitehead, Trans.). In A. Philips (Ed.), The Penguin Freud reader (pp. 435-540). London: Penguin. 
Freud, S. (1914). Remembering, Repeating and Working-Through (Further Recommendations on the Technique of Psycho-Analysis II). The Standard Edition of the Complete Psychological Works of Sigmund Freud, Volume XII (1911-1913). London: Hogarth Press.

Gallop, J. (2000). The ethics of reading: Close encounters. Journal of Curriculum Theorizing, 16(3), 7-17.

Garrett, H. J. (2017). Learning to be in the world with others: Difficult knowledge and social studies education. New York: Peter Lang.

Grumet, M. (1998). Lost spaces, potential places, and possible worlds: Why we read books with other people. Journal of Curriculum Theorizing, 14(2), 24-28.

Klein, M. (1937/1964). Love, guilt, and reparation. In M. Klein \& J. Riviere (Eds.), Love, hate and reparation (pp. 57-119). London: Norton.

Kuhn, A. (2000). A journey through memory. In S. Radstone (Ed.), Memory and methodology (pp. 179-196). New York: Berg.

LaCapra, D. (2001). Writing history, writing trauma. Baltimore, MD: JHU Press.

Lemieux, A., \& Lacelle, N. (2016). Mobilizing students' interpretive resources: A novel take on subjective response in the literature classroom. Language and Literacy, 18(3), 50-68.

McCloud, S. (1993). Understanding comics: The invisible art. New York: Paradox Press.

Matthews, S. (2009). Hitler's car as curriculum text: Reading adolescents reading history. Journal of the Canadian Association for Curriculum Studies, 7(2), 49-85.

The NPD Group, Inc. (2017, October 6). Comics and graphic novels one of highest growth categories in publishing [Press release]. Retrieved from https://www.npd.com/wps/portal/npd/us/news/press-releases/2017/comics-andgraphic-novels-one-of-highest-growth-categories-in-publishing-reports-npd/

Pazzagli, A, \& Monti, M. R. (2010). Psychoanalysis and art: Artistic representations in patients' dreams. Psychoanalytic Quarterly, 79(3), 731-752.

Robertson, D.A. \& Henderson S.B. (2012). 7 generations: A Plains Cree saga. Winnipeg, MB: Highwater Press.

Rosenblatt, L. M. (1994). The reader, the text, the poem: The transactional theory of the literary work. Carbondale and Edwardsville, IL: Southern Illinois UP.

Segal, H. (1973). Introduction to the work of Melanie Klein. London: Hogarth Press.

Serafini, F. (2015). Paths to interpretation: Developing students' interpretive repertoires. Language and Literacy, 17(3), 118-133.

Simon, R. I. (2011). A shock to thought: Curatorial judgment and the public exhibition of "difficult knowledge." Memory Studies, 4(4), 432-449.

Stern, D. B. (2017). Unformulated experience, dissociation, and nachträglichkeit. Journal of Analytical Psychology, 62(4), 501-525.

Tamaki, J., \& Tamaki, M. (2008). Skim. Toronto, ON: Groundwood Books.

Telgemeier, R. (2012). Drama. New York: Scholastic.

Treacher, A. (2000). Children: Memories, fantasies and narratives: From dilemma to complexity. In Radstone, S (Ed.), Memory and methodology (pp. 133-153). New York: Berg.

Wilde, L. (2015). Yo miss: A graphic kook at high school. Portland, OR: Microcosm. Winnicott, D. W. (2005). Playing and reality. New York: Routledge. 
Wolfreys, J. (2000). Readings: Acts of close reading in literary theory. Edinburgh: Edinburgh UP.

Zembylas, M. (2014). Theorizing "difficult knowledge" in the aftermath of the "affective turn": Implications for curriculum and pedagogy in handling traumatic representations. Curriculum Inquiry, 44(3), 390-412.

\section{Author Biography}

David Lewkowich is an assistant professor in the Faculty of Education at the University of Alberta. His research interests include reading experience, psychoanalytic theory, and representations of teachers in comics and graphic novels.

Nicholas Jacobs (BA, MPS) is a Doctoral Student in the Department of Secondary Education at the University of Alberta. 